\title{
The genomic architecture of inversion clines in a grasshopper species group with a complex biogeographic history
}

\author{
Noelia Guzman ${ }^{1}$, Petri Kemppainen ${ }^{2}$, Daniela Monti ${ }^{1}$, Elio Castillo ${ }^{3}$, Marcela Rodriguero ${ }^{1}$, \\ Andres Sanchez-Restrepo ${ }^{1}$, Maria Cigliano $^{4}$, and Viviana Confalonieri ${ }^{1}$ \\ ${ }^{1}$ UBA Faculty of Exact and Natural Sciences \\ ${ }^{2}$ Affiliation not available \\ ${ }^{3}$ Universidad Nacional de Misiones Facultad de Ciencias Exactas Quimicas y Naturales \\ ${ }^{4}$ Universidad Nacional de la Plata
}

August 4, 2021

\begin{abstract}
Chromosomal inversions play a role in the adaptation and diversification of different systems, mainly due to supergenes resulting from recombination suppression. Supergenes are "clusters" of genes in linkage disequilibrium (LD) whose frequencies may be associated with environmental variables. The grasshopper "species complex" Trimerotropis pallidipennis is considered to have several genetic lineages distributed from North to South America in arid and semi-arid high-altitude environments. The southernmost lineage, Trimerotropis sp., bears 4 to 7 putative inversion polymorphisms with clinal variation, possibly allowing adaptation to temperate environments. We analyzed chromosomal, mitochondrial and genome-wide SNP markers in 19 Trimerotropis sp. populations mainly distributed along two altitudinal gradients (MS and Ju). We show that populations across Argentina are formed by two main chromosomally and genetically differentiated lineages: one distributed in the southernmost border of the "Andes Centrales", adding evidence for a differentiation hotspot in this area; and the other widely distributed in Argentina. Within the latter, genomic architecture analysis revealed four clusters of loci in high LD that correspond to inversions, of which at least one is associated to a chromosomal rearrangement, confirming its status as "true inversion". We demonstrated the stability of chromosome polymorphisms for more than 20 generations and the occurrence of non-neutral markers associated with inversions and environmental variables. Inversion clines could be the consequence of coupling between extrinsic postzygotic barriers, leading to a hybrid zone, and spatially varying selection along environmental gradients. These results provide a framework for future investigations about candidate genes implicated in the rapid adaptation to new environments.
\end{abstract}

\section{Hosted file}

Guzman et al_with tracked changes.doc available at https://authorea.com/users/325232/ articles/532784-the-genomic-architecture-of-inversion-clines-in-a-grasshopper-speciesgroup-with-a-complex-biogeographic-history

\section{Hosted file}

Guzman et al_without tracked changes.doc available at https://authorea.com/users/325232/ articles/532784-the-genomic-architecture-of-inversion-clines-in-a-grasshopper-speciesgroup-with-a-complex-biogeographic-history

\section{Hosted file}

Figura_1.eps available at https://authorea.com/users/325232/articles/532784-the-genomicarchitecture-of-inversion-clines-in-a-grasshopper-species-group-with-a-complex-

biogeographic-history 

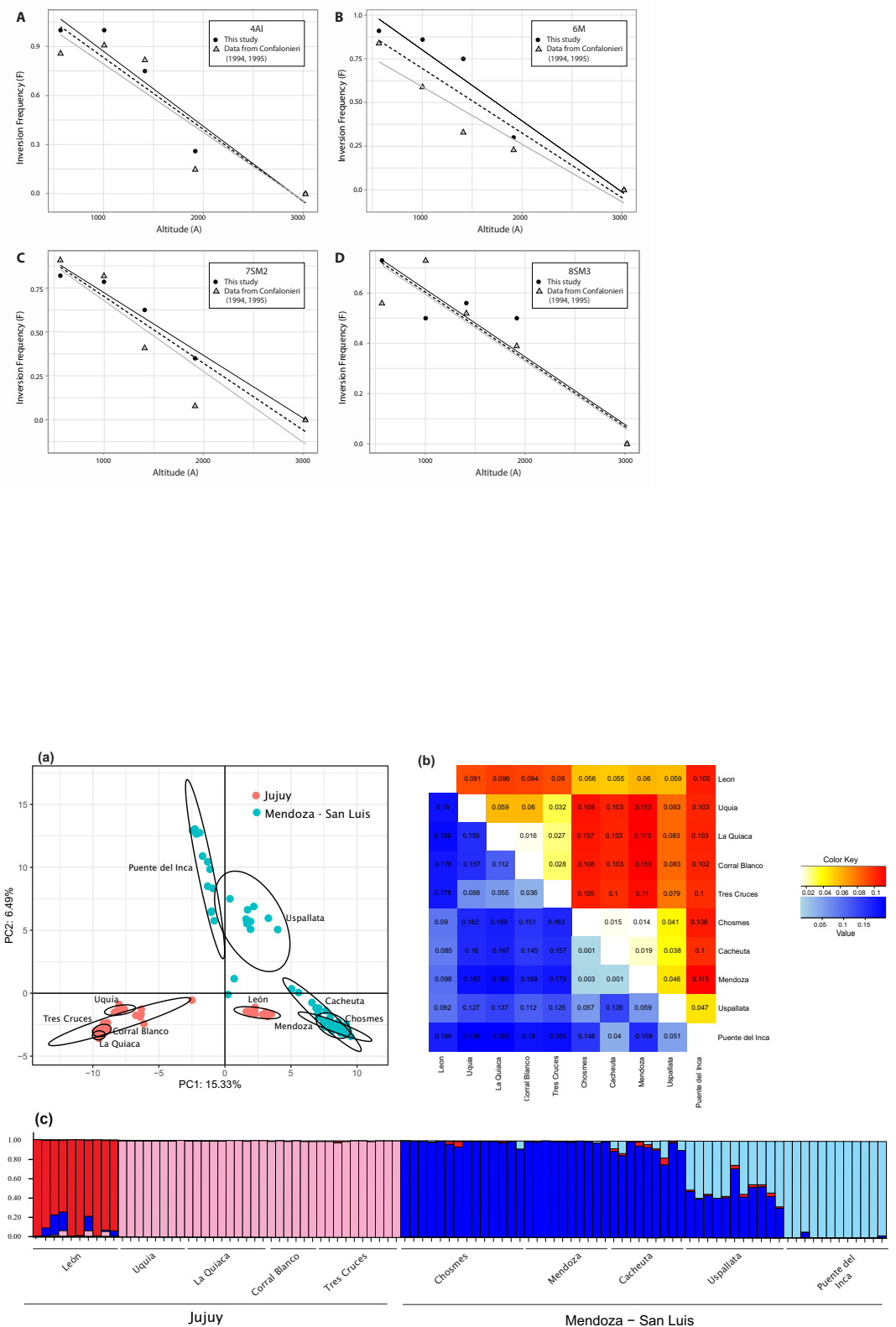


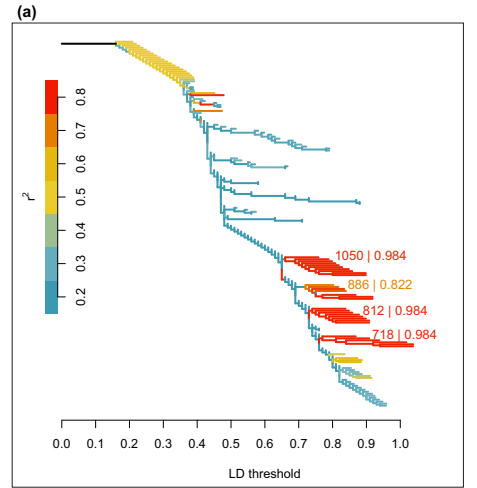

(b)

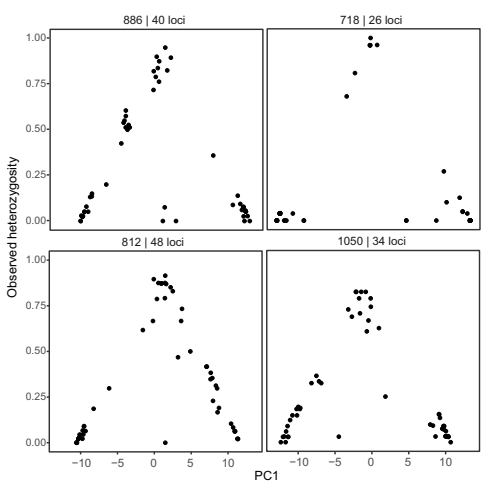

(c)

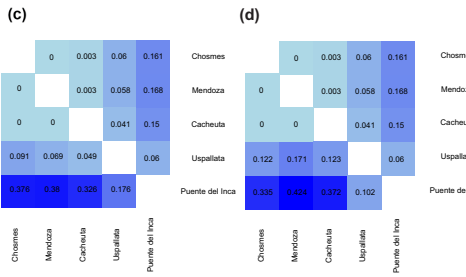

(e)

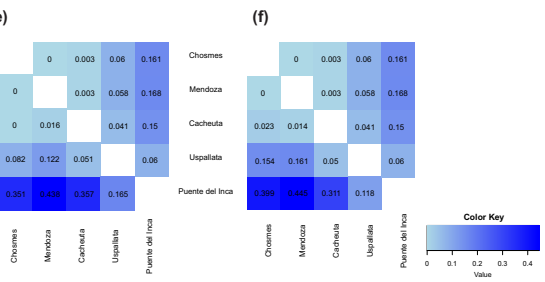




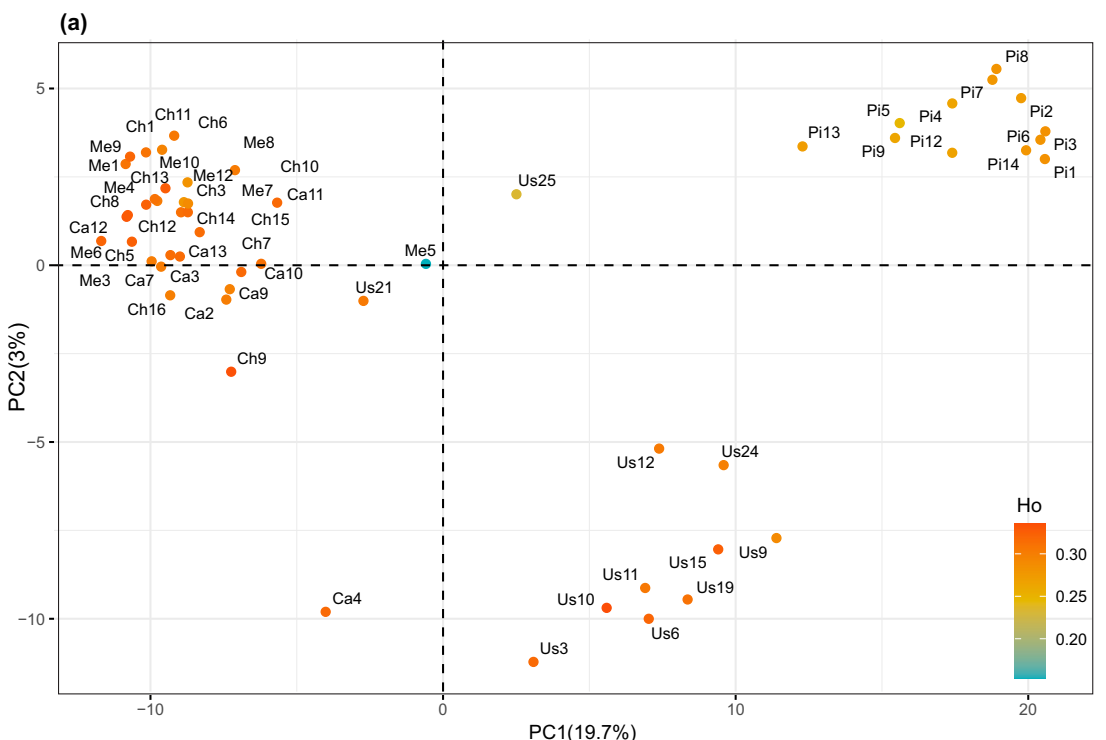

(b)

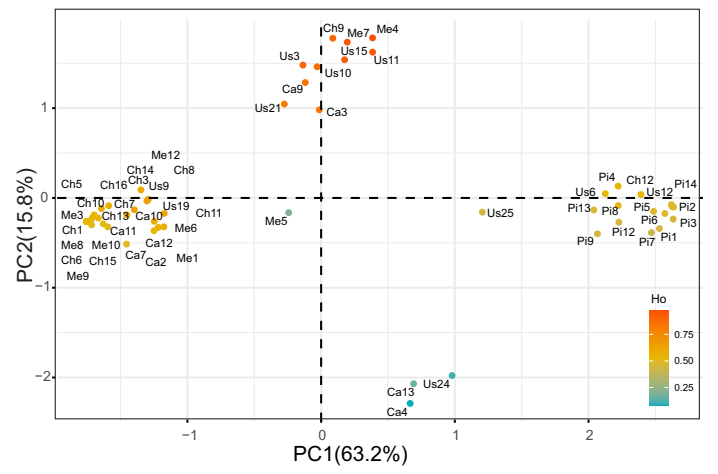

(c)

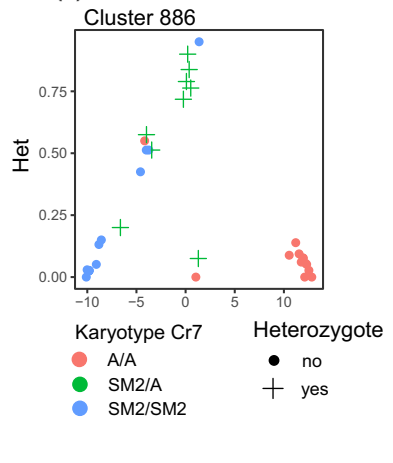




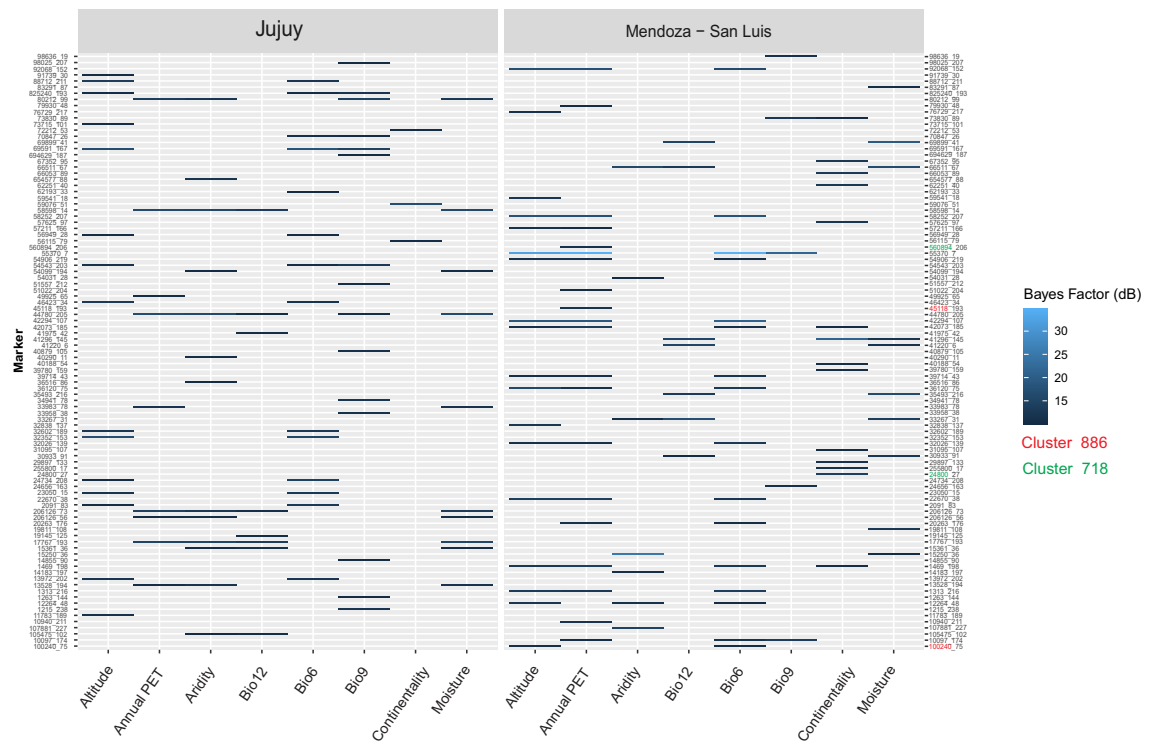

